\title{
In Silico and In Vitro: Identifying New Drugs
}

\author{
Ivani Pauli ${ }^{1}$, Luis Fernando Saraiva Macedo Timmers ${ }^{1}$, Rafael Andrade Caceres ${ }^{1,2}$, Milena Botelho \\ Pereira Soares ${ }^{3}$ and Walter Filgueira de Azevedo Jr. ${ }^{1,2, *}$
}

\begin{abstract}
${ }^{1}$ Faculdade de Biociências, Laboratório de Bioquímica Estrutural, Pontifícia Universidade Católica do Rio Grande do Sul, Porto Alegre - RS, Brazil; ${ }^{2}$ Programa de Pós-Graduação em Medicina e Ciências da Saúde. Programa de PósGraduação em Biologia Celular e Molecular. Pontifícia Universidade Católica do Rio Grande do Sul, Porto Alegre RS, Brazil and ${ }^{3}$ Centro de Pesquisas Gonçalo Moniz, Fundação Oswaldo Cruz. Rua Waldemar Falcão, 121. Candeal 40296-710 - Salvador, BA - Brazil
\end{abstract}

\begin{abstract}
Drug development is a high cost and laborious process, requiring a number of tests until a drug is made available in the market. Therefore, the use of methods to screen large number of molecules with less cost is crucial for faster identification of hits and leads. One strategy to identify drug-like molecules is the search for molecules able to interfere with a protein function, since protein interactions control most biological processes. Ideally the use of in silico screenings would make drug development faster and less expensive. Currently, however, the confirmation of biological activity is still needed. Due to the complexity of the task of drug discovery, an integrated and multi-disciplinary approach is ultimately required. Here we discuss examples of drugs developed through a combination of in silico and in vitro strategies. The potential use of these methodologies for the identification of active compounds as well as for early toxicity and bioavailability is also reviewed.
\end{abstract}

Key Words: Protein target, drug development, in silico screening, in vitro screening, pharmacokinetics.

\section{INTRODUCTION}

Protein-protein and protein-ligand interactions (PPIs, PLIs) control most biological processes, and the prospect of manipulating macromolecular complexes, either by blocking or stabilizing molecular interactions, holds promise for generating novel therapeutic agents as well as tools to improve our understanding of biochemical pathways [1-6]. The process of drug development involves several steps, from target identification and screening, hit and lead generation and optimization, preclinical and clinical studies to final registration of a drug [7]. Several methodologies can be employed in order to identify drug-like molecules able to interfere with a protein function, including in silico, in vitro, and in vivo tests. These vary regarding the amount of a certain molecule to be assayed, with time and costs and, consequently, in the number of molecules to be tested.

Although ultimately tests in animals and humans are required, there is a need to develop methods using in silico and in vitro tests in order to decrease the number of animals used in experimentation, as well as time and cost of drug development. Because undesired toxicity and pharmacokinetic properties are the main reasons for failures during drug development process [8], efforts have been made aiming to render in silico [9] and in vitro $[10,11]$ tests capable of selecting molecules with desired features earlier in the pipeline of drug development. In the past few years in vitro methods, which can be adapted to high throughput screenings (HTS), have been introduced by all major pharmaceutical companies

*Address correspondence to this author at the Av. Ipiranga, 6681, CEP 90619-900, Porto Alegre, Rio Grande do Sul, Brazil; Tel: +55-5133203500; E-mail: walter@azevedolab.net for preclinical prediction of metabolic properties of drug candidates. Development and rapid progress of in vitro drug metabolism testing methods have resulted in screening of a large number of new chemical entities and in generation of large amount of data [10]. In vitro methods may also enhance the knowledge of the drug metabolism processes as well as the mechanisms, e.g. for drug-drug interactions.

One key concept to understand the process of drug discovery is the definition of hit. Activity criterion for hit identification may vary for each drug discovery project. To illustrate the basic ideas underlying this definition consider the criterion for hit activity for development of drugs against protozoa, such as Plasmodium falciparum and Trypanosoma brucei rhodesiense. Hits against these organisms should present IC50 values below $0.2 \mu \mathrm{g}$ per $\mathrm{ml}$ [12]. With this information, and considering Lipinski's rule of five [13], concerning the molecular weight cutoff of an orally administered compound (molecular weight should be less than $500 \mathrm{Da}$ ) [13], we reach an IC50 value below $0.4 \mu \mathrm{M}$. To use a more flexible approximation, we may take a cutoff of $1 \mu \mathrm{M}$, to consider a molecule a hit. This cutoff value is also employed to identify hits for CDK2 (Cyclin-Dependent Kinase 2) [1417] and for human Purine Nucleoside Phosphorylase [1823].

Molecular biophysical methods, such as NMR and crystallography and high-throughput screening (HTS) experiments have all been shown efficient for hit finding [24-27]. However, a major drawback of these experimental approaches is the cost, with screening campaigns easily reaching hundred thousands to millions of dollars [28-30]. On the other hand, with the advent of computational technology, the in silico strategies have been successfully applied to identify 
catalytic sites. Targeting PPLs is still considered as extremely challenging. This kind of interactions depends on the topology, physicochemical nature and malleability of the interface area. In fact, several molecules disrupting PPIs and PPLs have already been reported, often through a combination of in silico and in vitro strategies [31-34] and these studies definitively open new avenues for therapeutic interventions. Considering the complexity of the task of drug discovery, an integrated and multi-disciplinary approach is required. With this in mind, the purpose of this review is to present some recent studies in which these methodologies were able to identify molecules which modulate proteinligand interactions through combined in silico and in vitro screening experiments.

\section{STRUCTURE-PROPERTY RELATIONSHIP}

Chemoinformatic approaches combined with structural bioinformatics and appropriate experimental approaches are nowadays well established and help to prioritize, design, analyze and rationalize experiments, and facilitate the design of new therapeutic compounds. Chemoinformatics can be used to identify "drug-like" molecules. The concept of druglikeness may be considered as an overall feature concerning several structural and physicochemical aspects [35]. This may be expressed as an index. There are many drug-likeness indices that may be used to guide prediction of structureproperty relationship (SPR). One landmark work in this field is the Lipinski's rule of five [13], which is used to estimate solubility and permeability in drug discovery. These guidelines predict that poor passive absorption or permeation of an orally administered molecule is more prone to occur if this drug satisfies at least two of the following rules:

1) Molecular weight higher than $500 \mathrm{Da}$,

2) High lipophilicity $(\mathrm{cLog} \mathrm{P}>5)$,

3) More than 5 intermolecular hydrogen-bond donors,

4) More than 10 intermolecular hydrogen-bond acceptors.

Fig. (1a and 1b) show binary complexes involving CDK2 and roscovitine and $\mathrm{PNP}$ and immucillin- $\mathrm{H}$, respectively. Both molecules satisfy the Lipinski's rule of five, as we can see in Table 1.

Small-molecule databases employ the Lipinski's guidelines to select subsets of drug-like molecules. This idea has been implemented in the ZINC database [36], which contains over a million molecules and presents subsets where molecules following Lipinski's rules are available for download, which may be used for virtual screening initiatives. In addition to the rule of 5 , other features can also be taken into consideration in order to identify orally bioavailable drug candidates, such as the number of rotatable bonds [37] and the polar surface area [38].

\section{ABSORPTION, DISTRIBUTION, METABOLISM, EXCRETION AND TOXICITY (ADMET)}

Drug discovery was traditionally carried out by testing synthesized compounds in a time-consuming multi-step process against a battery of in vivo biological screens. Pharmacokinetic properties and potential toxicity were only investigated at the development process and adverse findings were often made at this stage [8]. Then the projects would be halted or restarted to find another clinical candidate, becoming a big burden on the research and development budget of any pharmaceutical company.

Fortunately, this paradigm has been overcome in several ways. As the capacity for biological screening and chemical synthesis has dramatically increased, so have the demands for large quantities of early information on absorption, distribution, metabolism, excretion and toxicity data (together called ADMET data). Various media and high-throughput in vitro ADMET screens are therefore now in use. In addition, there is an increasing need for good tools for predicting these

(a)

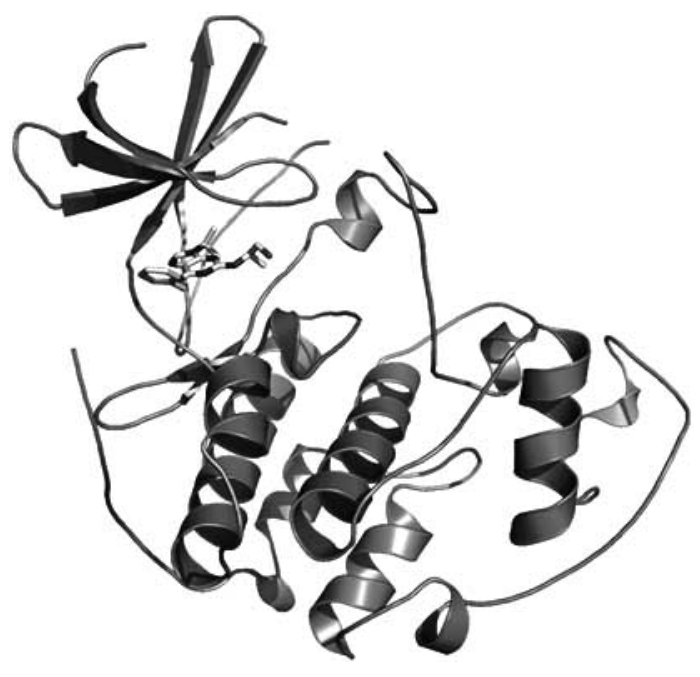

(b)

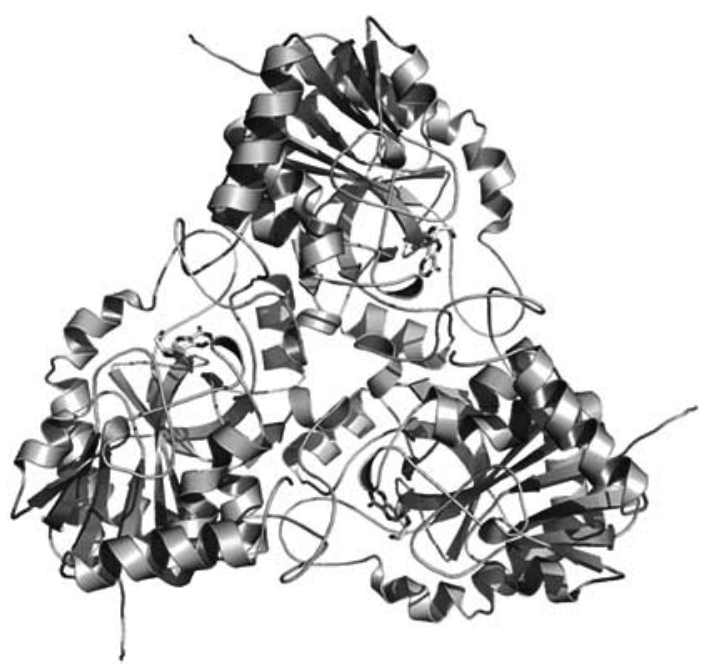

Fig. (1). Binary complexes involving CDK2 and roscovitine (a) and PNP and immucillin-H (b). 
Table 1. Molecular Descriptors for Roscovitine and Immucillin-H

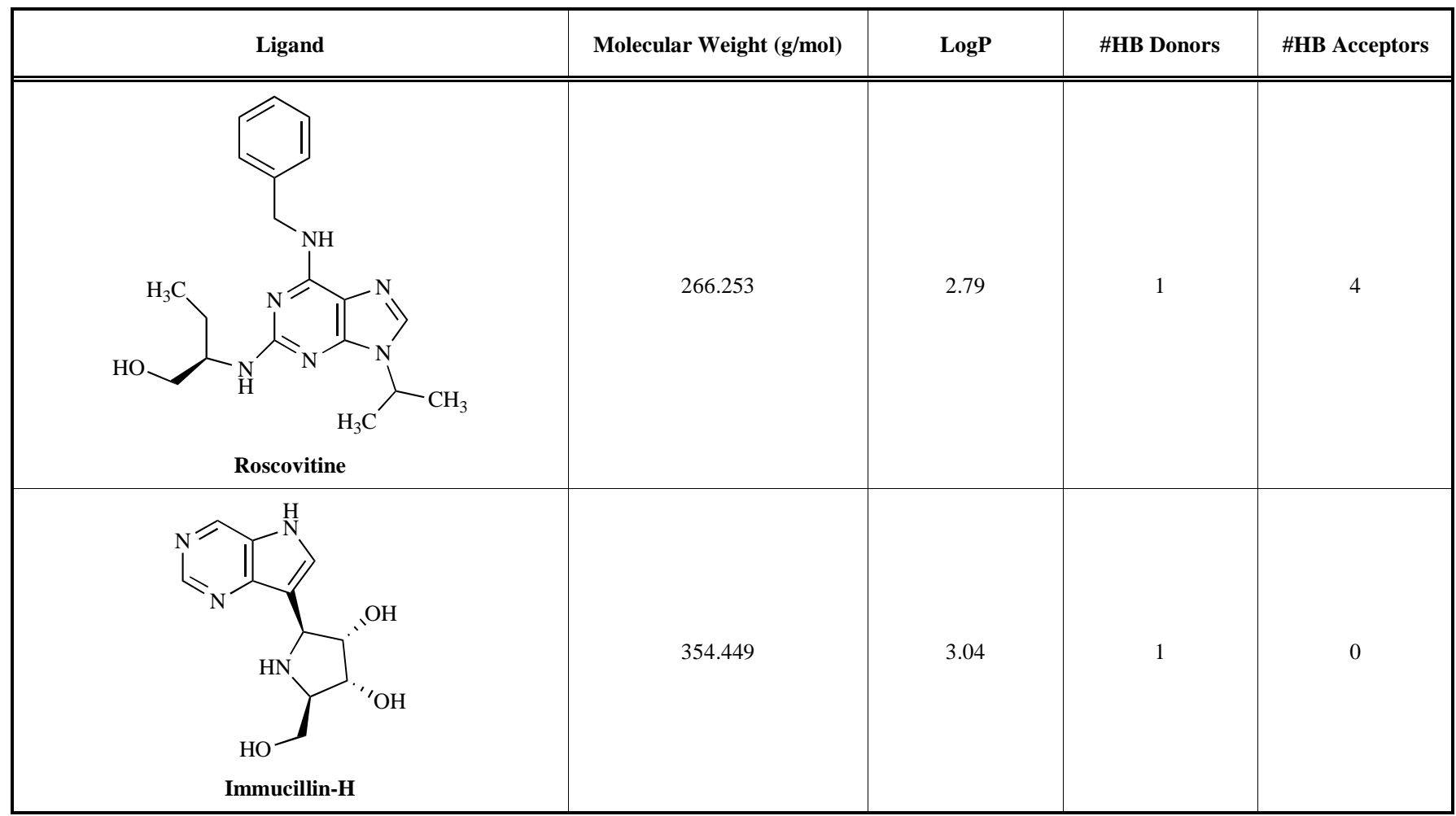

properties to serve two key aims - first, at the design stage of new compounds and compound libraries so as to reduce the risk of late-stage attrition and second, to optimize the screening and testing by looking only the most promising compounds [9].

Early, fast and relevant ADMET data is tackled in three ways. First, a variety of in vitro assays have been further automated through the use of robotics and miniaturization. Second, in silico models are being used to assist in the selection of subsets of compounds to go through these screens. Third, predictive models have been developed that might ultimately become sophisticated enough to replace in vitro assays and/or in vivo experiments [9].

ADMET data are needed when the design of new compounds is started and can influence the decision to proceed with synthesis either via traditional medicinal chemistry or combinatorial chemistry strategies. At this stage, computational approaches are the only option to obtain this information [9]. A deeper understanding of the relationships between important ADMET parameters and molecular structure properties have been used to develop in silico models that allow early estimation of several ADMET properties [39-45].

These models require three-dimensional structural information on the protein, which can be built by homology modeling [46-48] of related structures if the three-dimensional protein structure is not available. If no structural information on the protein is available, an alternative way of assessing the potential of a small molecule to interact with a particular protein is to use pharmacophore models, which are built from a superposition of known substrates of the protein
$[9,49]$. For data modeling, quantitative structure-activity relationship (QSAR) approaches [50] are typically applied.

The first generation of predictive ADMET models is now commercially available and others have been published and can now be implemented [51,52]. In the short term, these tools should allow concentrating on compounds with the highest chances of meeting the required pharmacokinetic and safety criteria, and should contribute to a reduction in late stage compound attrition [9].

\section{CASE STUDIES}

The development of a drug requires the analysis of a large amount of data. For example, activity against a range of targets has to be measured to ensure that the compounds have not only good activity against their intended target, but also good selectivity with respect to a range of other targets. When it comes to rationalizing results, many other parameters have to be considered, such as molecular weight, $\log P$, and $\mathrm{p} K_{\mathrm{a}}$. The handling of such large amounts of data requires dedicated software.

Several software programs are available for the handling of data which allow medicinal chemists to assess biological activity versus physical properties, or to compare the activities of a series of compounds at two different targets. Recent reviews summarize the development of such approaches [9,53-58]. These programs permit results to be presented in a visual qualitative fashion, allowing a quick identification of any likely correlations between different sets of data. Other programs can be used to assess the biological results from a combinatorial synthetic study [59]. 
It is interesting to say here that it was once claimed that drugs could be designed using molecular modeling alone [59]. However, no drug has been designed purely by this method so far. The following case studies illustrate how in vitro and computer methods (in silico) have been used as an aid in drug design.

\section{FINDING NOVEL ANXIOLYTIC AND ANTIDEPRES- SANT AGENTS}

The project described below was carried out by SmithKline Beecham and was aimed at finding novel anxiolytic and antidepressant agents [60-64]. The first step was to find a suitable protein target. In this case the choice was to design an antagonist for a serotonin receptor. Serotonin (or 5hydroxytryptamine) is an important neurotransmitter in the central nervous system, and abnormalities in its level are related to a variety of disorders such as anxiety, depression, and migraine. Serotonin receptor antagonists are therefore useful in treating these diseases. The discovery of various types of serotonin receptors allows the possibility of designing antagonists more selective in their action and with fewer side effects, as a result [59].

There are several types of serotonin receptors $\left(5-\mathrm{HT}_{1}-5\right.$ $\mathrm{HT}_{7}$ ) with many subtypes. For $5-\mathrm{HT}_{2}$ receptor there are three subtypes (A, B and $\mathrm{C}$ ). The $5 \mathrm{HT}_{2 \mathrm{C}}$ receptor is of particular interest because there is evidence of its role in anxiety. At the time that this project was being developed there was no selective serotonin antagonists for $5-\mathrm{HT}_{2 \mathrm{c}}$ available in the market and therefore the premise was that a selective antagonist would have improved properties over established drugs [59]. In this study we can see a typical example of the advantages to ally in vitro, in vivo, and in silico methods to develop a more efficacious new drug, as summarized below.

\section{Lead Compound to SB 200646}

Lead compound to SB 200646 [60]. The lead compound for the project was a drug that had been produced by Lilly Pharmaceuticals. One of the problems with this compound was its insolubility in water, and so it was decided to replace the phenyl ring with a more polar pyridine ring (ring variation). Among various analogues tested the 3- and 5- substitution, respectively, were ideal (substituent variation). Finally the methyl and ethyl substituents on the indole ring were not essential to the biological activity and could be absent (simplification). The final compound proved to be the first selective $5 \mathrm{HT}_{2 \mathrm{~B} / 2 \mathrm{C}}$ antagonist, having modest $5 \mathrm{HT}_{2 \mathrm{C}}$ affinity in vitro, some oral activity in vivo, and a 50-fold selectivity over the closely related $5 \mathrm{HT}_{2 \mathrm{~A}}$ receptor.

\section{SB 200646 to SB 206553}

SB 200646 to SB 206553 [61]. The urea functional group is the most flexible region of SB 200646. The rigidification was rationalized by a molecular modeling study aiming at a reduction of the total number of conformations maintaining the active conformation. It lead to SB 206553, resulting in a 10 -fold increase in in vitro affinity and in a 160-fold selectivity over the $5-\mathrm{HT}_{2 \mathrm{~A}}$ receptor. The compound was also shown to relieve anxiety in vivo, with a 4-fold increase in potency in the rat hypolocomotion assay. Unfortunately, this compound was found to undergo metabolisation in the body, resulting in N-demethylation and production of a nonselective, active metabolite.

Many strategies were tried in order to replace or stabilize the metabolically labile N-methyl group of SB 206553. After the synthesis of several analogues, molecular modeling was carried out to overlay both active and inactive compounds, using the urea group as the common feature. A model of 5$\mathrm{HT}_{2 \mathrm{C}}$ receptor was built using molecular modeling software and used for docking SB 206553 into the binding site. This allowed the identification of the features responsible for the affinity and specificity of this compound against the $5-\mathrm{HT}_{2 \mathrm{C}}$ receptor.

\section{SB 206553 to SB 221284}

SB 206553 to SB 221284 [62]. The metabolically labile $N$-methyl group had to be removed, but it was important to replace it with something that could fit the identified hydrophobic pocket in order to retain selectivity. In this study, the in vivo evaluation was allied to in silico methods, which involved molecular modeling studies, Quantitative-Structure Activity Relationship (QSAR) analysis, and Comparative Molecular Field Analysis (CoMFA) studies. Molecular modeling was used to model the receptor and to obtain a threedimensional model for the binary complex involving receptor and drug. QSAR analysis is concerned with mathematical modeling connecting chemical structure and pharmacological activity in a quantitative approach for a set of compounds. Methods which can be used in QSAR include various regression and pattern recognition techniques. CoMFA methods could be defined as a 3D-QSAR method that employs statistical correlation methods for the analysis of the quantitative relationship between the biological activity of a set of compounds with a specified alignment, and their threedimensional electronic and steric properties. The main goal of CoMFA is to derive a correlation between the identified biological activity of a set of compounds and their threedimensional, electrostatic and intermolecular hydrogen bonds features. In conclusion, the authors reported the synthesis and biological activity of a series of substituted 1-(3pyridylcarbamoyl)-indolines which illustrates the use of 5,6disubstituted monocyclic rings as $N$-methylindole isosteres in the context of $5-\mathrm{HT}_{2 \mathrm{C} / 2 \mathrm{~B}}$ receptor antagonists. Compound SB 221284 was selected on the basis of its overall biological profile for further evaluation as a potential, novel, nonsedating anxiolytic agent. Unfortunately, these compounds were found to be potent inhibitors of several human cytochrome P450 enzymes which precluded their further development [63]. A CoMFA analysis of these compounds produced a model with good predictive value and, in addition, good qualitative agreement both with our $5-\mathrm{HT}_{2 \mathrm{C}}$ receptor model and with proposed binding mode for this class of ligands within that model.

\section{SB 221284 to SB 228357}

SB 221284 to SB 228357 [64]. A series of biarylcarbamoylindolines has been identified with excellent $5-\mathrm{HT}_{2 \mathrm{C}}$ affinity and selectivity over the $5-\mathrm{HT}_{2 \mathrm{~A}}$ receptor. In addition, bispyridyl ether carbamoylindolines have been identified with additional selectivity over the closely related $5-\mathrm{HT}_{2 \mathrm{~B}}$ receptor. These compounds are inverse agonists at the hu- 
man $5-\mathrm{HT}_{2 \mathrm{C}}$ receptor, completely abolishing basal activity in a functional Protease inhibitor (PI) assay. This series has reduced P450 inhibitory liability compared to a previously described series of 1-(3-pyridylcarbamoyl) indulines from which they evolved. Some analogues demonstrated excellent oral activity in a rat pharmacodynamic model and in animal models of anxiety. On the basis of the favorable biological profile, SB 228357 has been selected for further development to determine its therapeutic potential for the treatment of CNS disorders, such as depression and anxiety.

\section{HIV PROTEASE INHIBITORS}

The acquired Immunodeficiency syndrome (AIDS) pandemic was first recognized in 1981 in Los Angeles, California $[65,66]$ and has been spreading continuously. The HIV/AIDS pandemic has quickly advanced to become one of the great plagues of all times, now affecting between 30.6 and 36.1 million persons worldwide and causing more than 2.08 million deaths per year [65, 67]. The HIV is a retrovirus that utilizes the genomic RNA to generate a viral DNA. In common with other retroviruses, human immunodeficiency virus (HIV), the causative agent of AIDS, codes for a proteinase that plays an essential role in the virus replication cycle. Inhibition of HIV proteinase is, therefore, a potential therapeutic approach for the treatment of AIDS [68,69]. There are two main types of HIV, type 1 (HIV-1) and type 2 (HIV-2). HIV-1 is the most prevalent in the worldwide pandemic, whereas HIV-2 is present mainly in West Africa, where it was discovered in 1986 [70,71].

Discovery of highly active antiretroviral therapy (HAART) represents a significant advance in the management of AIDS [72,73]. As one of the crucial ingredients in HAART, protease inhibitors (PIs) play an important role in preventing the replication of HIV. Although several HIV PIs have been used in clinical practice, emergence of viral resistance [74,75], adverse side effects [76-81] and high costs of the production have limited their utilization. Development of novel HIV PIs against multi-drug resistant viral strains with unique profiles is still urgently required for HAART [82].

In the mid 1990s, the use of X-ray crystallographic and molecular modeling approaches led to structure-based design of a series of inhibitors which act on the viral enzyme HIV protease. The HIV protease belongs to the family of "aspartyl proteases". These enzymes catalyze the cleavage of peptide bonds and contain an aspartic acid in the active site that is crucial to the catalytic mechanism. The enzyme is relative small (HIV protease is a dimer made up of two identical protein units, each consisting of 99 amino acids), and can be obtained by synthesis. Alternatively, it can be cloned and expressed in fast-growing cells, then purified in large quantities. The enzyme is easily crystallized with or without an inhibitor bound to the active site, and this meant that it has proved to be an ideal candidate for structure-based drug design [59]. In recent years, target based drug design has been greatly aided by high-resolution 3D crystallographic structures of proteins and computer aided drug design (CADD). HIV-1 protease provides an elegant example of the successful application of drug design [83].

The development of new inhibitors for the HIV protease has become an interesting area of study when was discov- ered that it could cleave bonds between a proline residue and aromatic residues, which do not occur with mammalian proteases. Based on the specificity of these proteases, several proteases inhibitors were designed to act as transition-state inhibitors, allying in silico and in vitro techniques, as described below.

\section{Saquinavir}

It was the first HIV protease inhibitor to enter clinical trials in 1991 and the first protease inhibitor on the market in December 1995 [83], being developed by Roche. Received approval from the US Food and Drug Administration (FDA) in 1994 and since then has been re-formulated twice in order to address bioavailability and tolerability issues. Currently saquinavir is rarely used in HIV therapy [84].

\section{Ritonavir}

This drug was developed by Abbott Pharmaceuticals, and it was the first to exploit the unique symmetry of the HIV-1 protease dimer for the design of inhibitors based upon $\mathrm{C} 2$ symmetry. Inhibitors were designed to bind in such a way as to superimpose their symmetry axis with that of the HIV-1 protease, and to maximize intermolecular interactions with the enzyme subsites [84]. Fig. (2) shows the intermolecular hydrogen bonds observed in the complex HIV proteaseritonavir, where the aspartic catalytic residues can be clearly seen.

\section{Indinavir}

It was developed by Merck and approved by the FDA in March 1996. A key contribution in the development of HIV proteases inhibitors with the hydrokyethylene isostere moiety was the discovery of benzocycloalkyl amines as novel Cterminal. The indinavinir has better oral bioavailability than saquinavir and is less bound to plasma proteins (60\%) [59].

\section{Nelfinavir}

The development of nelfinavir was based on work carried out by Lylli company. It was marketed in 1997 and is used as part of a four-drug combination therapy. This drug inhibits the metabolic enzyme CYP3A4 and thus affects the plasma levels of other drugs metabolized by this enzyme. It is $98 \%$ bound to plasma proteins [59].

\section{Palinavir}

A highly potent and specific inhibitor of HIV-1 and HIV2 proteases, leads to inhibition of viral replication in cell culture. On the basis of potency and oral bioavailability in various animal models, palinavir was isolated from a collection of hydroxyethylamine-based inhibitors containing a substituted pipecolinic amide. As previously described [85], palinavir is a selective and potent inhibitor of HIV-1 protease with antiviral activity against laboratory strains, clinical isolates, and reverse transcriptase (RT) inhibitor-resistant isolates.

\section{Amprenavir}

It was designed by Vertex Pharmaceuticals as a nonpeptide-like protease inhibitor using saquinavir as the lead 


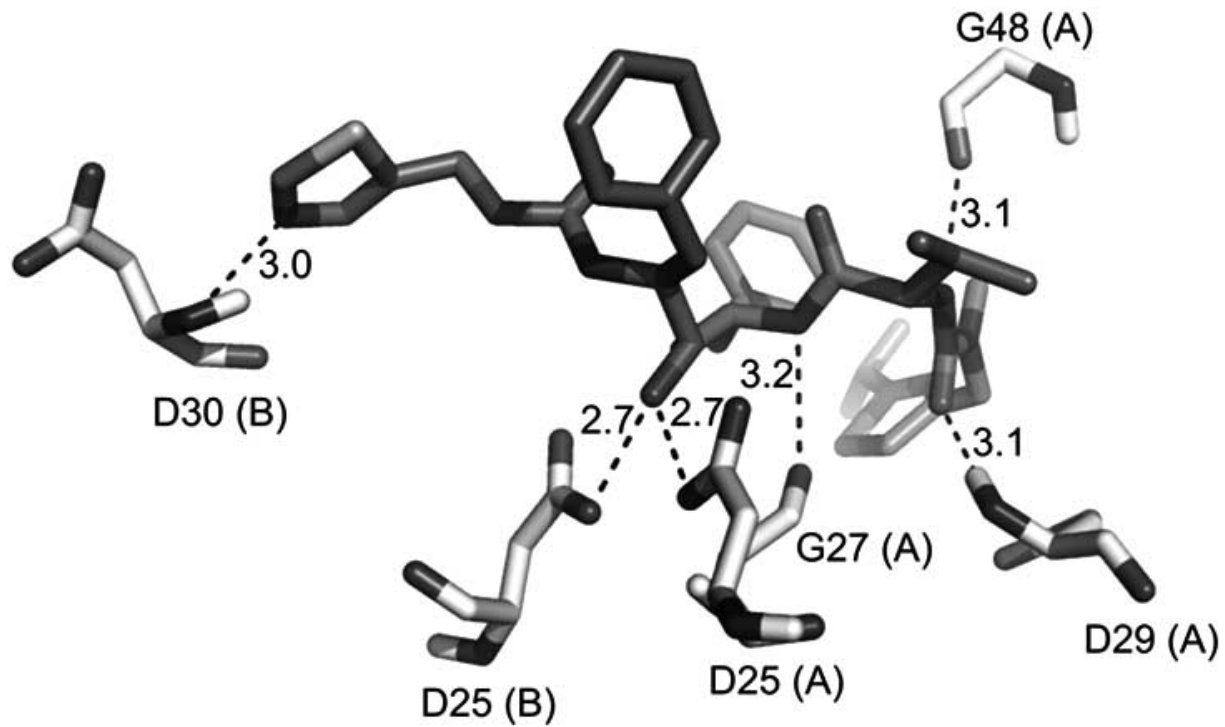

Fig. (2). Intermolecular hydrogen bonds observed in the complex HIV protease-ritonavir, where the aspartic catalytic residues can be clearly seen. D (aspartic residues), G (glutamine). All the distances between the atoms are measured in $\AA$. The letters A and B in parenthesis represent each of the HIV protease structure complexes.

compound. The protease inhibitor amprenavir was licensed to GlaxoWellcome and approved in 1999 [59].

\section{Atazanavir}

In June 2003, received marketing approval from the FDA for the treatment of HIV-1 infection in combination with other antiretroviral agents $[86,87]$. Atazanavir is an azapeptide HIV-1 protease inhibitor that target protease enzyme, ultimately resulting in the creation of noninfectious viral particles. The inhibitor displays antiretroviral activity against laboratory and primary HIV isolates in cell lines and peripheral blood mononuclear cells in the absence of serum proteins [88].

\section{FINAL REMARKS}

A great progress has been made to develop approaches, such as molecular dynamics, molecular docking and ADMET prediction, and these are evolving into methodologies powerful enough to accelerate and reduce the costs of drug development process. In addition, the success of the computational experiments reveals valuable new information on the molecular mechanisms underlying cellular mechanics. Examples of this success are proteins already studied by computational approaches, such as the muscle protein titin [9092], the cytoskeleton protein spectrin [92,93], and the ubiquitous protein ankyrin [94].

\section{REFERENCES}

[1] Yin, H. and Hamilton, A.D. (2005) Angew Chem. Int. Ed. Engl., 44(27), 4130-4163.

[2] Lipinski, C. and Hopkins A. (2004) Nature, 432(7019), 855-861.

[3] Zheng, C.; Han, L.; Yap, C.W.; Xie, B. and Chen, Y. (2006) Drug Discov. Today, 11(9-10), 412-420.

[4] Harris, C.J. and Stevens, A.P. (2006) Drug Discov. Today, 11(1920), 880-888.

[5] Hall, S.E. (2006) Drug Discov. Today, 11(11-12), 495-502.

[6] Stockwell, B.R. (2004) Nature, 432(7019), 846-854.

[7] Bleicher, K.H.; Böhm, H.J.; Muller, K. And Alanine, A.I. (2003) Nat. Rev. Drug Discov., 2(5), 369-378.
[8] Kennedy, T. (1997) Drug Disc. Today, 2, 436-444.

[9] van de Waterbeemd, H. and Gifford, E. (2003) Nat. Rev. Drug Discov., 2(3), 192-204.

[10] Baranczewski, P.; Stanczak, A.; Sundberg, K.; Svensson, R.; Wallin, A.; Jansson, J.; Garberg, P. and Postlind, H. (2006) Pharmacol. Reports, 58(4), 453-472.

[11] Dambach, D.M.; Andrews, B.A. and Moulin, F. (2005) Toxicol. Pathol., 33(1), 17-26.

[12] Nwaka, S. and Hudson, A. (2006) Nat. Rev. Drug Discov., 5(11), 941-955

[13] Lipinski, C.A.; Lombardo, F.; Dominy, B.W. and Feeney, P.J. (2001) Adv. Drug Deliv. Rev., 46(1-3), 3-26.

[14] De Azevedo, W.F.; Mueller-Dieckmann, H.J.; Schulze-Gahmen, U.; Worland, P.J.; Sausville, E. and Kim, S.H. (1996) Proc. Natl. Acad. Sci. USA, 93(7), 2735-2740.

[15] De Azevedo, W.F.; Leclerc, S.; Meijer, L.; Havlicek, L.; Strnad, M. and Kim, S. H. (1997) Eur. J. Biochem., 243(1-2), 518-526.

[16] Canduri, F. and De Azevedo, W.F.Jr. (2005) Curr. ComputerAided Drug Design, 1(1), 53-64.

[17] Canduri, F.; Perez, P.C.; Caceres, R.A. and de Azevedo, W.F.Jr. (2008) Med. Chem., 4(3), 210-218.

[18] De Azevedo, W.F.; Canduri, F.; Santos, D.M.; Silva, R.G.; Oliveira, J.S.; Carvalho, L.P.S.; Basso, L.A.; Mendes, M.A.; Palma, M.S. and Santos, D.S. (2003) Biochem. Biophys. Res. Commun., 308(3), 545-552.

[19] Santos, D.M.; Canduri, F.; Pereira, J.H.; Dias, M.V.B.; Silva, R.G.; Mendes, M.A.; Palma, M.S.; Basso, L.A.; De Azevedo, W.F. and Santos, D.S. (2003) Biochem. Biophys. Res. Commun., 308(3), 553559.

[20] De Azevedo, W.F.; Canduri, F.; Dos Santos, D.M.; Pereira, J.H.; Dias, M.V.B.; Silva, R.G.; Mendes, M.A.; Basso, L.A.; Palma, M.S. and Santos, D.S. (2003) Biochem. Biophys. Res. Commun., 309(4), 917-922.

[21] Canduri, F.; Fadel, V.; Dias, M.V.B.; Basso, L.A.; Palma, M.S.; Santos, D.S. and De Azevedo, W.F.Jr. (2005) Biochem. Biophys. Res. Commun., 326(3), 335-338.

[22] Canduri, F.; Fadel, V.; Basso, L.A.; Palma, M.S.; Santos, D.S. and De Azevedo, W.F.Jr. (2005) Biochem. Biophys. Res. Commun. 327(3), 646-649.

[23] Canduri, F.; Silva, R.G.; dos Santos, D.M.; Palma, M.S.; Basso, L.A.; Santos, D.S. and De Azevedo, W.F.Jr. (2005) Acta. Crystallogr. D. Biol. Crystallogr. 61(7), 856-862.

[24] Davis, A.M.; Teague, S.J. and Kleywegt, G.J. (2003) Angew Chem. Int. Ed. Engl., 42(24), 2718-2736.

[25] Jahnke, W. (2007) J. Biomol. NMR, 39(2), 87-90. 
[26] Babaoglu, K. and Shoichet, B.K. (2006) Nat. Chem. Biol., 2(12), 720-723.

[27] Anderson, A.C. (2003) Chem. Biol., 10(9), 787-797.

[28] Takeuchi, K. and Wagner, G. (2006) Curr. Opin. Struct. Biol., 16(1), 109-117.

[29] Davies, J.W.; Glick, M. and Jenkins, J.L. (2006) Curr. Opin. Chem. Biol., 10(4), 343-351.

[30] Stevens, R.C. (2003) Drug Discov. World, 4(1), 35-48.

[31] Whitty, A. and Kumaravel G. (2006) Nat. Chem. Biol., 2(3), 112118.

[32] Collins, I. and Workman, P. (2006) Nat. Chem. Biol., 2(12), 689700.

[33] Arkin, M. (2005) Curr. Opin. Chem. Biol., 9(3), 317-324.

[34] Timmers, L.F.S.M.; Caceres, R.A.; Vivan, A.L.; Gava, L.M.; Dias, R.; Ducati, R.; Basso, L.A.; Santos, D.S. and de Azevedo, W.F.Jr. (2008) Arch. Biochem. Biophys., 479(1), 28-38.

[35] Schneider, G. and Baringhaus, K.H. (2008) in Molecular Design. Concepts and Applications. Wiley-VCH Verlag $\mathrm{GmbH} \&$ Co. KGaA, Weinheim.

[36] Irwin, J.J. and Shoichet, B.K. (2005) J. Chem. Inf. Model., 45(1), $177-182$

[37] Veber, D.F.; Johnson, S.R.; Cheng, H.Y.; Smith, B.R.; Ward, K.W. and Kopple, K.D. (2002) J. Med. Chem., 45(12), 2615-2623

[38] Clark, D.E. and Picket, S.D. (2000) Drug Discov. Today, 5(2), 4958

[39] Janssen, D. (2002) Curr. Drug Disc., 1(1), 38-40

[40] Podlogar, B.L.; Muegge, I. and Brice L.J. (2001) Curr. Opin. Drug Disc. Dev. 4(1), 102-109.

[41] Ekins, S.; Waller, C.L.; Swaan, P.W.; Cruciani, G.; Wrighton, S.A. and Wikel, J.H. (2001) J. Pharmacol. Toxicol. Methods, 44 (1), 251-272.

[42] Ekins, S. and Wrighton, S.A. (2001) J. Pharmacol. Toxicol. Methods, 45(1), 65-69.

[43] Rodrigues, A.D.; Winchell, G.A. and Dobrinska, M.R. (2001) J. Clin. Pharmacol., 41(4), 368-373.

[44] Bachman, K.A. and Ghosh, R. (2001) Curr. Drug Metab., 2(3), 299-314.

[45] Selick, H.E.; Beresford, A.P. and Tarbit, M.H. (2002) Drug Disc. Today, 7(2), 109-116.

[46] Greer, J.; Erickson, J.W.; Baldwin, J.J. and Varney, M.D. (1994) J. Med. Chem., 37(8), 1035-1054.

[47] Leach, A.R. (2001) in Molecular modeling: principles and applications, $2^{\text {nd }}$ edn. Pearson Education, London.

[48] Navia, M.A. and Murcko, M.A. (1992) Curr. Opin. Struct. Biol., 2(1), 202-216.

[49] Sun, H. (2008) Curr. Med. Chem. 15(10), 1018-1024.

[50] van de Waterbeemd H. and Rose S. (2003) in The Practice of Medicinal Chemistry 2nd (Wermuth, L. G., Ed) (Academic Press) pp. 1367-1385.

[51] van de Waterbeemd H. (2002) Curr. Opin. Drug Disc. Dev. 5(1), 33-43.

[52] Clark, D.E. and Grootenhuis, P.D. (2002) Curr. Opin. Drug Disc. Dev., 5(3), 382-390.

[53] Demel, M.A.; Schwaha, R.; Krämer, O.; Ettmayer, P.; Haaksma, E.E.; and Ecker, G.F. (2008) Expert Opin. Drug. Metab. Toxicol., 4(9), 1167-1180.

[54] Khan, M.T. and Sylte, I. (2007) Curr. Drug Discov. Technol., 4(3), $141-149$

[55] Dearden, J.C. (2007) Expert Opin. Drug Metab. Toxicol., 3(5), 635-639.

[56] Mohan, C.G.; Gandhi, T.; Garg, D. and Shinde, R. (2007) Mini Rev. Med. Chem., 7(5), 499-507.

[57] Norinder, U. and Bergström, C.A. (2006) Chem. Med. Chem. 1(9), 920-937.

[58] Stumpf, W.E. (2005) J. Pharmacol. Toxicol. Methods, 51(1), 2540.

[59] Patric, G.L. (2005) in An Introduction to Medicinal Chemistry Antiviral Agents. Oxford University Press Inc., New York. pp. 440-488.

[60] Blackburn, T.P.; Suzuki, K. and Ashby, C.R.Jr. (2006) Synapse, 59(8), 502-512.
[61] Bromidge, S.M.; Dabbs, S.; Davies, D.T.; Davies, S.; Duckworth, D.M.; Forbes, I.T.; Gadre, A.; Ham, P.; Jones, G.E.; King, F.D.; Saunders, D.V.; Thewlis, K.M.; Vyas, D.; Blackburn, T.P.; Holland, V.; Kennett, G.A.; Riley, G.J.; and Wood, M.D. (1999) Bioorg. Med. Chem., 7(12), 2767-2773.

[62] Bromidge, S.M.; Dabbs, S.; Davies, D.T.; Duckworth, D.M.; Forbes, I.T.; Ham, P.; Jones, G.E.; King, F.D.; Saunders, D.V.; Starr, D.; Thewlis, K.M.; Wyman, P.A.; Blaney, F.E.; Naylor, C.B.; Bailey, F.; Blackburn, T.P.; Holland, V.; Kennett, G.A. Riley, G.J. and Wood, M.D. (1998) J. Med. Chem., 41(10), 15981612 .

[63] Bromidge, S.M.; Duckworth, M.; Forbes, I.T.; Ham, P.; King, F.D.; Thewlis, K.M.; Blaney, F.E.; Naylor, C.B.; Blackburn, T.P.; Kennett, G.A.; Wood, M.D. and Clarke, S.E. (1997) J. Med. Chem., 40(22), 3494-3496.

[64] Bromidge, S.M.; Dabbs, S.; Davies, D.T.; Davies, S.; Duckworth, D.M.; Forbes, I.T.; Gaster, L.M.; Ham, P.; Jones, G.E.; King, F.D. Mulholland, K.R.; Saunders, D.V.; Wyman, P.A.; Blaney, F.E.; Clarke, S.E.; Blackburn, T.P.; Holland, V.; Kennett, G.A.; Lightowler, S.; Middlemiss, D.N.; Trail, B.; Riley, G.J. and Wood, M.D. (2000) J. Med. Chem. 43(6), 1123-1134.

[65] Kempen, J.H. (2008) Indian J. Ophthalmol., 56(5), 385-90.

[66] Centers for Disease Control. Pneumocytis pneumonia-Los Angeles. (1981) MMWR Morb Mortal Wkly Rep., 30, 250-252.

[67] UNAIDS Annual Report 2007: Know Your Epidemic. UNAIDS, Geneva, Available at: /data.unaids.org/pub/Report/2008/jc11535_ annual_report07_en.pdf

[68] Whittle, P.J. and Blundell, T.L. (1994) Annu. Rev. Biophys. Biomol. Struct., 23, 349-379.

[69] Blundell, T.L.; Lapatto, R.; Wilderspin, A.F.; Hemmings, A.M.; Hobart, P.M.; Danley, D.E; Whittle, P.J. (1990) Trends Biochem. Sci., 15(11), 425-430.

[70] Menendez-Arias, L. and Tozser, J. (2007) Trends Pharmacol. Sci., 29(1), $42-49$

[71] Clavel, F.; Guetard, D.; Brun-Vezinet, F.; Chamaret, S.; Rey, M.A.; Santos-Ferreira, M.O.; Laurent, A.G.; Dauguet, C.; Katlama, C. and Rouzioux, C. (1986) Science, 233(4761), 343-346.

[72] Zhou, L.; Yang, Q.; Wang, Y.; Hu, Y.; Luo, X.; Bai, D. and Li, S (2008) Chem. Pharm. Bull., 56(8), 1147-1152.

[73] Palella, F.J.Jr.; Delaney, K.M.; Moorman, A.C.; Loveless, M.O.; Fuhrer, J.; Satten, G.A.; Aschman, D.J. and Holmberg, S.D. (1998) N. Engl. J. Med., 338(13), 853-860.

[74] Mocroft, A.; Vella, S.; Benfield, T.L.; Chiesi, A.; Miller, V.; Gargalianos, P.; d`Arminio Monforte, A.; Yust, I.; Bruun, J.N.; Phillips, A.N. and Lundgren, J.D. (1998) Lancet, 352(9142), 17251730

[75] Condra, J.H.; Schleif, W.A.; Blahy, O.M.; Gabryelski, L.J.; Graham, D.J.; Quintero, J.C.; Rhodes, A.; Robbins, H.L.; Roth, E. and Shivaprakash, M. (1995) Nature, 374(6522), 569-571.

[76] Boden, D. and Markowitz, M. (1998) Anitimicrob. Agents Chemother., 42(11), 2775-2783.

[77] Walli, R.; Herfort, O.; Michl, G.M.; Demant, T.; Jager, H.; Dieterle, C.; Bogner, J.R.; Landgraf, R. and Goeble, F.D. (1998) AIDS, 12(15), 167-173.

[78] Lo, J.C.; Mulligan, K.; Tai, V.W.; Algren, H. and Schambelan, M. (1998) Lancet, 351(9106), 867-870.

[79] Miller, K.D.; Jones, E.; Yanovski, J.; Shankar, R.; Feuerstein, I. and Falloon, J. (1998) Lancet, 351(9106), 871-875.

[80] Carr, A.; Samaras, K.; Burton, S.; Law, M.; Freund, J.; Chisholm, D.J. and Cooper, D.A. (1998) AIDS, 12(7), 51-58

[81] Viraben, R. and Aquilina, C. (1998) AIDS, 12(), 37-39.

[82] Martinez, E.; Casamitjana, R.; Conget, I. and Gatell, J.M. (1998) AIDS, 12(15), 2077-2079.

[83] Tomasselli, A.G. and Heinriskson, R.L. (2000) Biochim. Biophys. Act., 1477(1-2), 189-214.

[84] Youle, M. (2007) J. Antimicrob. Chemother., 60(6), 1195-205.

[85] Lamarre, D.; Croteau, G.; Wardrop, E.; Bourgon, L.; Thibeault, D.; Clouette, C.; Vaillancourt, M.; Cohen, E.; Pargellis, C.; Yoakim, C. and Anderson, P.C. (1997) Antimicrob. Agents Chemother., 41(5), 965-971.

[86] Musial, B.L.; Chojnacki, J.K. and Coleman, C.I. (2004) Am. J. Health-Syst. Pharm., 61(13), 1365-1374. 
[87] Orrick, J.J. and Steinhart, C.R. (2004) Ann. Pharmacother., 38(10), 1664-1674.

[88] Robinson, B.S.; Riccardi, K.A.; Gong, Y.; Guo, Q.; Stock, D.A.; Blair, W.S.; Terry, B.J.; Deminie, C.A.; Djang, F.; Colonno, R.J. and Lin, P. (2000) Antimicrob. Agents Chemother., 44(8), 20932099.

[89] Lu, H.; Isralewitz, B.; Krammer, A.; Vogel, V. and Schulten, K. (1998) Biophys. J., 75(2), 662-671.

[90] Lu, H. and Schulten, K. (2000) Biophys. J., 79(1), 51-65.
[91] Gao, M.; Lu, H. and Schulten, K. (2002) J. Muscle Res. Cell Motil., 23(5-6), 513-521.

[92] Ortiz, V.; Nielsen, S.O.; Klein, M.L. and Discher, D.E. (2005) J. Mol. Biol., 349(3), 638-647.

[93] Paramore, S. and Voth G. A. (2006) Biophys. J., 91(9), 3436-3445.

[94] Sotomayor, M.; Corey, D.P. and Schulten, K. (2005) Structure, 13(4), 669-682. 